\title{
Comparative analysis of 2 commercial molecular tests for the detection of gastroenteric viruses on stool samples
}

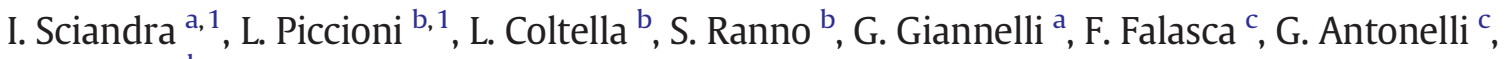 \\ C. Concato ${ }^{\mathrm{b}}, \mathrm{O}$. Turriziani ${ }^{\mathrm{c}, *}$ \\ a National Institute of Gastroenterology “S. de Bellis", Research Hospital, Castellana Grotte, Italy \\ b Virology Unit, Bambino Gesù Children's Hospital, Rome, Italy \\ c Department of Molecular Medicine, Sapienza University, Rome, Italy
}

\section{A R T I C L E I N F O}

\section{Article history:}

Received 24 May 2019

Received in revised form 14 August 2019

Accepted 30 August 2019

Available online $\mathrm{xxxx}$

\section{Keywords:}

Gastroenteritis

Enteric viruses

Syndromic testing

Molecular diagnostic

Multiplex real-time PCR

\begin{abstract}
A B S T R A C T
Objective: Our purpose was to compare the performance of 2 recently introduced molecular tests for the identification of gastrointestinal viral infections.

Methods: One hundred fecal samples from pediatric patients were analyzed using 2 workflows, each including nucleic acids extraction and multiplex Real-Time PCR: Allplex ${ }^{\mathrm{TM}}$ GI-Virus Assay and FTD Viral gastroenteritis. The agreement was evaluated calculating Cohen's kappa and applying McNemar's test.

Results and conclusion: Allplex and FTD assays showed 100\% overall agreement for Norovirus GI/GII and Sapovirus ( Rotavirus (91\%, k: 0.53), owing to samples resulted positive only with FTD test. The discrepancies were attributed to a different efficiency of extraction/amplification and to the different Adenovirus serotype specificity of the tests since Allplex detects only AdVF40 and AdVF41.

FTD test should be used when non enteric adenovirus could have a clinical significance.
\end{abstract}

(c) 2019 Elsevier Inc. All rights reserved.

\section{Background}

Gastrointestinal infections and diarrhea are a leading cause of morbidity and mortality worldwide; although the global health community is exerting great effort towards the prevention and control of this phenomenon, in 2016 diarrheal disease was the eighth leading cause of global death among all ages and the fifth among children younger than 5 years (Troeger et al. 2018). Several viral pathogens, like Rotavirus (RoV), Norovirus (NoV), human Adenovirus (AdV), human Astrovirus $(\mathrm{AsV})$, and Sapovirus $(\mathrm{SaV})$, play a well-established role in acute gastroenteritis onset, while the actual responsibility in disease of other recently discovered enteric viruses is less clear (Oude Munnink and Van der Hoek 2016).

Enteric viral infections are generally self-limiting but can be responsible for severe disease in some high-risk patients. In children younger than 5 years of age, for example, RoV is responsible for almost $40 \%$ of hospital admissions and, in 2016, accounted for 128,000 deaths at a global level (Bányai et al. 2018). The increase in diarrhea mortality in over-70 patients, especially in high-income settings, has now become a public health problem, and RoV and AdV are respectively the second

\footnotetext{
* Corresponding author: Tel.: +39-06-49974298; fax: +39-0649974296.

E-mail address: ombretta.turriziani@uniroma1.it (O. Turriziani).

${ }^{1}$ These authors made an equal contribution to this work.
}

and third cause of death in this category (Troeger et al. 2018). Moreover, chronic infection can occur in immunocompromised patients of all ages and was reported for NoV, RoV, AdV, AsV and SaV (Daniel-Wayman et al. 2018; Ghosh et al. 2017; Petrignani et al. 2018; Roos-Weil et al. 2011; Wunderli et al. 2011; Ye et al. 2015).

Since the clinical identification of viral gastroenteritis can be misleading, laboratory diagnosis is mandatory for the proper management and treatment of gastroenteric disorders, especially for the high-risk patient groups mentioned above, as well as for the prevention of transmission during outbreaks. Several sensitive and effective molecular methods have been developed, and laboratory practice is shifting towards syndromic testing thanks to multiplex gastrointestinal panels (Ramanan et al. 2018).

\section{Objectives}

The aim of this work was to evaluate and compare the performance of 2 recently introduced molecular tests for the identification of gastrointestinal viral infections: the Allplex ${ }^{\mathrm{TM}}$ GI-Virus assay (Seegene, Seoul, Korea) and the FTD Viral Gastroenteritis assay (Fast Track Diagnostics, Luxembourg). Both tests are designed to identify NoV, RoV, AdV, AsV, and $\mathrm{SaV}$, but differ in AdV species detection, as Allplex assay is specific for 40 and 41 serotypes (F species), while FTD detects all 57 accepted human adenovirus types (HAdV-1-57) in seven species (A-G). 


\section{Study design}

\subsection{Specimens}

This study was performed at the Virology Units of Umberto I University Hospital and Bambino Gesù Children's Hospital in Rome (Italy). One hundred fecal samples from pediatric patients collected in 2017 were retrospectively analyzed. Samples were chosen randomly among stools previously tested with a commercial RoV and AdV immunochromatographic assay due to suspect gastroenteritis, and then stored at $-20^{\circ} \mathrm{C}$ for eventual further analysis.

Patient records and information were anonymized and de-identified prior to analysis. Ethical approval was obtained from the Institutional Review Board (CE5283 n.114/19). Each sample was split into 2 aliquots for subsequent extraction and molecular testing on 2 different analytical platforms. Assays were performed according to the manufacturer's instructions, as follows. All sample extracts were stored at $-80{ }^{\circ} \mathrm{C}$ to allow subsequent analysis in case of discordant results.

\subsection{Siemens workflow}

Fecal samples were suspended in $400 \mu \mathrm{L}$ PBS, homogenized by vortexing and centrifuged at $13500 \mathrm{rpm}$ for 2 minutes. Two hundred microliters of supernatant were mixed with $600 \mu \mathrm{L}$ of lysis buffer and extracted (Versant SP 1.0 Reagents, Siemens Healthcare Diagnostics, Tarrytown, NY). After elution in $50 \mu \mathrm{L}, 10 \mu \mathrm{L}$ of nucleic acid extract were mixed with each of the three master mixes of the FTD Viral Gastroenteritis kit (Fast Track Diagnostics, Luxembourg), in a final volume of $25 \mu \mathrm{L}$. Extraction and amplification were performed on Versant kPCR Molecular System (Siemens Healthcare Diagnostics, Tarrytown, NY).

\subsection{Seegene workflow}

Stool samples were suspended in $1000 \mu \mathrm{L}$ ASL Buffer and were processed by Allplex ${ }^{\mathrm{TM}}$ GI-Virus assay (Seegene, Seoul, Korea). Fifty microliters of supernatant was extracted using the STARMag Universal Cartridge kit (Seegene, Seoul, Korea) on automated Nimbus IV platform and eluted in $100 \mu \mathrm{L}$ of elution buffer. Real time PCR was performed on CFX96 (Bio Rad) with Gastrointestinal panel assay kit, using $5 \mu \mathrm{L}$ of DNA/RNA in a final volume of $25 \mu \mathrm{L}$. The panel is made up of $1 \mathrm{mix}$.

An internal control was included in each sample to check both extraction efficiency and PCR inhibition.

In every run, a negative control was used to monitor carry-over contamination. The results were analyzed automatically using Seegene software (Seegene Viewer V2.0).

\subsection{Analysis of discordant samples}

Sample extracts from Seegene or Siemens workflow showing discrepant results for AdV were analyzed with the AdV R-gene (bioMérieux) and submitted to sequencing analysis of the Adenovirus hexon gene hyper-variable regions 1-6 as described by Lu and Erdman (2006). For AdV positive stools with unidentified serotype and for discrepant RoV samples extracts from Siemens and Seegene, workflows were analyzed respectively with Allplex and FTD test.

\subsection{Statistical analysis}

The agreement of the 2 assays was evaluated by calculating Cohen's kappa and its 95\% confidence interval (CI), and by applying McNemar's test, where possible.
Table 1

Comparison of Allplex and FTD assays.

\begin{tabular}{|c|c|c|c|c|c|c|c|}
\hline & \multicolumn{4}{|c|}{ Allplex/FTD Results } & \multirow{2}{*}{$\begin{array}{l}\text { Overall } \\
\text { agreement }\end{array}$} & \multirow{2}{*}{$\begin{array}{l}\text { Cohen's к } \\
{[95 \% \mathrm{CI}]}\end{array}$} & \multirow{2}{*}{$\begin{array}{l}\text { McNemar's } \\
\text { test } \\
P \text {-value }\end{array}$} \\
\hline & $\mathrm{P} / \mathrm{P}$ & $\mathrm{P} / \mathrm{N}$ & $\mathrm{N} / \mathrm{P}$ & $\mathrm{N} / \mathrm{N}$ & & & \\
\hline $\begin{array}{l}\text { Norovirus } \\
\text { GI }\end{array}$ & 3 & 0 & 0 & 97 & $100 \%$ & 1.00 & NA \\
\hline $\begin{array}{l}\text { Norovirus } \\
\text { GII }\end{array}$ & 19 & 0 & 0 & 81 & $100 \%$ & 1.00 & NA \\
\hline Sapovirus & 2 & 0 & 0 & 98 & $100 \%$ & 1.00 & NA \\
\hline Adenovirus & 6 & 0 & 9 & 85 & $91 \%$ & $\begin{array}{l}0.53 \\
{[0.27-0.79]}\end{array}$ & $0.007^{*}$ \\
\hline Rotavirus & 67 & 0 & 11 & 22 & $89 \%$ & $\begin{array}{l}0.73 \\
{[0.58-0.87]}\end{array}$ & $0.002^{*}$ \\
\hline Astrovirus & 1 & 0 & 1 & 98 & $99 \%$ & $\begin{array}{l}0.66 \\
{[0.04-1.00]}\end{array}$ & 1.000 \\
\hline
\end{tabular}

Abbreviations: P, positive; N, negative; NA, not applicable; * $P<0.05$.

\section{Results}

The overall agreement between Allplex GI-Virus and FTD Viral GE assays was perfect (100\%) for Norovirus GI, Norovirus GII and Sapovirus, and very high for Astrovirus (99\%) (Table 1), with one discrepant sample that was positive only by FTD Viral GE analysis, probably owing to its low viral load ( $C_{t}$ value: 34.1$)$.

For AdV and RoV the overall agreement was lower, and the results obtained through the 2 assays differed significantly due to respectively 9 and 11 samples positive only with FTD test. Adenovirus discordant samples were further analyzed using a specific Real-Time PCR that confirmed the positivity of all samples; $C_{t}$ values detected with FTD workflow and Real-Time analysis were similar (Table 2). All 9 samples were sequenced to identify AdV serotype. For 7 samples the AdV type could be successfully assigned as non-F, thus explaining the negative results obtained by Allplex.

To assess whether discordant RoV results and the remaining AdV discordant samples could be explained by different efficiency of the extraction and/or amplification, FTD Viral GE multiplex PCR was performed on extracts from Seegene workflow and vice versa. For RoV, all 11 discrepant samples had RoV positive results using Allplex GI-Virus assay, with $C_{t}$ values ranging from 32.1 to 39.6 ; FTD Viral GE successfully amplified 8/11 samples extracted by Allplex workflow, with $C_{t}$ values between 26.8 and 38.4 (Table 3). The discordant RoV results were then interpreted as true positive samples with low viral load. As shown in table 3, Allplex did not amplify AdV in extracts from Siemens workflow, which indicates that the discrepancy could be due either to the different tests' specificity or to the low viral load. On the contrary both extracts from Allplex workflow were amplified by FTD Viral GE.

Overall, the FTD assay detected 77 monomicrobic infections and 20 coinfections involving $2(18 / 20)$ or three viruses (2/20), and the Allplex assay detected 77 monomicrobic infections and 10 polymicrobic infections with 2 viruses. Allplex did not identify 8 Adenovirus, 1 Astrovirus,

Table 2

Results from Adenovirus R-gene test, FTD assay and genotyping performed on AdV discordant samples.

\begin{tabular}{llll}
\hline Sample number & $\begin{array}{l}\text { Result }\left(C_{t} \text { value }\right) \\
\text { Adenovirus R-gene test }\end{array}$ & $\begin{array}{l}\text { Result }\left(C_{\mathrm{t}} \text { value }\right) \\
\text { FTD Viral GE }\end{array}$ & AdV genotype \\
\hline 7 & Positive (27.0) & AdV Positive (28.9) & $2 \mathrm{C}$ \\
16 & Positive (30.0) & AdV Positive (28.0) & $1 \mathrm{C}$ \\
19 & Positive (35.0) & AdV Positive (33.8) & $/$ \\
32 & Positive (31.8) & AdV Positive (30.9) & $2 \mathrm{C}$ \\
33 & Positive (34.8) & AdV Positive (33.0) & $/$ \\
34 & Positive (25.8) & AdV Positive (25.7) & 31 A \\
72 & Positive (28.8) & AdV Positive (26.9) & $2 \mathrm{C}$ \\
82 & Positive (22.4) & AdV Positive (22.8) & $1 \mathrm{C}$ \\
94 & Positive (34.6) & AdV Positive (33.6) & $2 \mathrm{C}$ \\
\hline
\end{tabular}

Abbreviations: $\mathrm{C}_{\mathrm{t}}=$ threshold cycle; $\mathrm{AdV}=$ Adenovirus 
Table 3

Analysis of RoV and AdV discordant samples.

\begin{tabular}{lll}
\hline $\begin{array}{l}\text { Sample } \\
\text { number }\end{array}$ & $\begin{array}{l}\text { Test FTD performed on } \\
\text { Seegene workflow extracts }\end{array}$ & $\begin{array}{l}\text { Test Allplex performed on } \\
\text { Siemens workflow extracts }\end{array}$ \\
\cline { 2 - 3 } & Result $\left(C_{\mathrm{t}}\right)$ & \\
\hline 7 & RoV Positive (28.94) & RoV Positive (35.54) \\
8 & RoV Positive (30.22) & RoV Positive (38.30) \\
12 & RoV Positive (30.50) & RoV Positive (34.03) \\
13 & RoV Positive (29.90) & RoV Positive (38.61) \\
19 & AdV Positive (33.65) & AdV Negative \\
33 & AdV Positive (32.36) & AdV Negative \\
34 & RoV Positive (26.89) & RoV Positive (32.12) \\
37 & RoV Negative & RoV Positive (37.57) \\
39 & RoV Negative & RoV Positive (39.62) \\
40 & RoV Positive (36) & RoV Positive (33.36) \\
41 & RoV Positive (36.76) & RoV Positive (36.32) \\
42 & RoV Negative & RoV Positive (36.78) \\
43 & RoV Positive (38.40) &
\end{tabular}

Abbreviations: $\mathrm{C}_{\mathrm{t}}=$ threshold cycle; $\mathrm{RoV}=$ Rotavirus

and 3 Rotavirus in coinfected samples (Table 4). Ten coinfections were identified by both assays and all involved RoV, which in $9 / 10$ cases was detected with lower $C_{t}$ values in respect with the other coinfecting virus (difference in $C_{t}$ values ranging from 1.95 to 23.88 for FTD and from 1.27 to 23.56 for Allplex); in only one case of Rov-AsV infection, the RoV $C_{t}$ value was higher for FTD, but lower for Allplex compared to the AsV $C_{t}$ value. Among the remaining 10 coinfections detected by FTD alone, NoV GII showed lower $C_{t}$ values than RoV and AdV (4/10, difference in $C_{t}$ values: 6.81-15.51), while RoV load was higher than AsV and $\operatorname{AdV}$ (6/10, difference in $C_{t}$ values: 15.37-21.17). Overall, in 16/20 cases the coinfecting viruses displayed a difference in $C_{t}$ values higher than 10.

\section{Discussion and conclusion}

The increasing availability of several syndromic panel-based tests implies a careful evaluation in order to select the test more suited to each diagnostic laboratory. In this work, we compare the performance of 2 commercial multiplex molecular assays, Allplex GI-Virus and FTD Viral GE, in terms of the detection, of enteric viruses usually associated with gastrointestinal infection and diarrhea.

Our data shows a perfect agreement between the 2 assays for NoV $\mathrm{GI} / \mathrm{GII}, \mathrm{AsV}$ and $\mathrm{SaV}$, but a significant discordance was revealed in the analysis of AdV and RoV. These findings are not consistent with a recent study where an agreement higher than $99 \%$ was observed for all viruses (Hirvonen 2019). Nonetheless, it is worth noting that in our population a higher prevalence of RoV and AdV was found. This finding could be ascribed to several factors, such as a poor RoV vaccination coverage in our country (Napolitano et al. 2019) and/or differences in RoV and AdV strains' circulation among geographical regions (Lynch and Kajon 2016, Sadiq et al. 2018).

Table 4

Coinfections detected by FTD and Allplex assays.

\begin{tabular}{llll}
\hline Coinfection & $\begin{array}{l}\text { Number of coinfected } \\
\text { samples detected } \\
\text { by FTD }\end{array}$ & $\begin{array}{l}\text { Number of coinfected } \\
\text { samples detected by } \\
\text { Allplex }\end{array}$ & $\begin{array}{l}\text { Virus not } \\
\text { detected by } \\
\text { Allplex }\end{array}$ \\
\hline AdV-RoV & 6 & 1 & AdV \\
AsV-RoV & 2 & 1 & AsV \\
NoV GI-RoV & 3 & 3 & - \\
Noro GII-RoV & 4 & 3 & RoV \\
Noro GII-AdV & 1 & 0 & AdV \\
RoV-SaV & 2 & 2 & - \\
Noro GII-AdV-RoV & 2 & 0 & AdV - RoV \\
\hline
\end{tabular}

Abbreviations: AdV = Adenovirus; RoV = Rotavirus; AsV = Astrovirus; $\mathrm{NoV}=$ Norovirus; SaV = Sapovirus
In our study, a higher number of positive RoV and AdV samples were identified by FTD. For RoV, this observation can be ascribed both to the molecular assays' performance and to the different extraction yields of the methods used. Indeed, the Allplex assay performed on Versant extracts from Siemens workflow produced positive RoV results for all the discordant samples, with higher $C_{t}$ values compared to FTD test. This data suggests a better performance of the Siemens workflow in the detection of samples with low viral load.

A high analytical sensitivity is one of the main advantages of molecular assays. However, on the other hand, the result interpretation can be difficult for positive samples with high $C_{t}$ value, given the virus shedding in stools for long periods following recovery from disease, and the frequent detection of viruses in fecal samples from asymptomatic subjects, especially children (Corcoran et al. 2014; Kapusinszky et al. 2012; Leva et al. 2016; Ye et al. 2017). Some authors suggest that the semi-quantitative determination of viral load through $C_{t}$ values analysis could be used to distinguish symptomatic from asymptomatic infections, and cut-off $C_{t}$ values were proposed for RoV and NoV (Bennett et al. 2015; Phillips et al. 2009a; Phillips et al. 2009b; Trang et al. 2015). Unfortunately, the lack of patients' clinical data does not allow us to study the correlation between $C_{t}$ values and severity of disease.

Another issue related to analytical sensitivity evidenced in this work is the high number of coinfections observed, and remarkably FTD detected more coinfected samples than Allplex. The high rate of coinfection is consistent with other laboratory-based studies focused on molecular diagnosis of gastrointestinal viruses (Binnicker 2015; Daniel-Wayman et al. 2018). Interestingly, in the majority of coinfected samples (16/20 for FTD and 7/10 for Allplex) the $C_{t}$ value detected for one of the viruses was substantially lower than the other, but again we could not match our results with clinical or epidemiological data. Further studies are needed to evaluate the correlation between viral loads of coinfecting viruses and disease, given the misleading interpretation that could be generated from multiple positivity for 2 or even three pathogens.

In the choice of a RoV test, it is also important to take into account that molecular assays are able to detect the attenuated RoV strains used in the vaccines, and thus an overdiagnosis of RoV infections in pediatric patients could occur. In a recent study $C_{t}$ values were significantly lower for wild-type RoV compared to detectable Rotarix strain, suggesting that in a vaccinated pediatric population a less sensitive test could have higher specificity and negative predictive value (Yandle et al. 2018). These observations highlight the importance that diagnostic laboratories select $C_{t}$ cut-off values based on the specific molecular assay used in order to better aid clinical patient management.

In addition, when choosing a syndromic approach, the AdV serotype specificity of the assay has to be considered. As shown by sequencing analysis, and consistently with its AdV 40/41 specificity, the Allplex test could not identify samples positive for non-enteric serotypes. Similar results were reported in another work comparing Allplex and genotyping assay (Hyun et al. 2018). Uncertainty remains about whether AdV species known to cause infection in other districts can be directly implicated in gastrointestinal disease, or rather reside physiologically in the gut. Several studies highlighted the great AdV serotype diversity in stool samples from both patients with diarrhea or healthy controls (Afrad et al. 2018; La Rosa et al. 2015; Lekana-Douki et al. 2015; Liu et al. 2014; Lu et al. 2017; Mayindou et al. 2016; Moyo et al. 2014; Primo et al. 2018; Ye et al. 2017), and in a case-control study Qiu et al. (2018) demonstrated that non-enteric AdV 3 was a high-risk factor for diarrhea. A wide range of serotypes has been detected also in stool samples from immunocompromised patients with a shift in predominance towards AdV-C species (Feghoul et al. 2015; McMillen et al. 2017; Mynarek et al. 2014); moreover, in this high-risk patient setting infections sustained by both enteric and non-enteric AdVs have strong clinical relevance for their ability to cause disseminated disease after reactivation. This is particularly significant in pediatric patients, where the frequency of invasive infection ranges from $6 \%$ to $42 \%$ after allogeneic 
hematopoietic stem cell transplantation (allo-HSCT), and can reach 38$57 \%$ after solid organ transplantation depending on the transplanted organ, reflecting the epidemiology of AdV infections that mainly occur at a young age (Lion 2014). It is important to note that several studies have brought forth evidence that in pediatric allo-HSCT recipients, AdV proliferation preceding invasive infection occurs in the gastrointestinal tract and, consequently, pre- and post-transplant molecular monitoring of fecal AdV load can effectively predict the risk of disseminated disease (Feghoul et al. 2015; Hum et al. 2018; Jeulin et al. 2011; Kosulin et al. 2016; Kosulin et al. 2018; Lion et al. 2010). Together, these findings strongly underline the importance of using broadspectrum AdV assays for the diagnostic screening of stool samples in immunocompromised pediatric patients. Furthermore, like for any other diagnostic methods, the variability, and especially reassortment, of viruses should be considered when a new test is used, because it may potentially lead to a different serotype not necessarily recognized by the current assays.

In conclusion, the overall agreement between Allplex GI Virus assay and FTD Viral Gastroenteritis assay was high for the detection of NoV, $\mathrm{SaV}$ and AsV, but a lower concordance was evidenced for AdV and RoV.

This result may be due to 2 different reasons. First, our data suggest that Siemens workflow has a better efficiency both in extraction and amplification of samples, resulting in the identification of AdV and RoV positive samples with low viral load, and in a higher number of coinfections. It should be underlined, however, that, although our sample size was obtained accordingly to Bujang \& Baharum in order to obtain a 90\% statistical power and an alpha value of 0.05 (Bujang and Baharum 2017), to our opinion further studies, possibly with a higher sample size, are needed to consolidate the better efficiency of Siemens workflow compared to the Seegene workflow.

Second, the difference in AdV specificity between the assays did not allow the detection by Allplex of non-F AdV. samples positive. Both these observations may have important practical implications, since, as stated above, the clinical significance of positive samples with high $C_{t}$ values is not fully understood and further studies are needed for their correct interpretation. Consequently, a more sensitive test could provide results of difficult evaluation. On the other hand, the range of AdV serotypes detected must be carefully considered, as the identification of non-enteric species could be of clinical relevance. Specifically, in immunocompromised pediatric patients the positivity for AdV in stools could provide timely information on the risk of disseminated disease, therefore multiplex assay, like FTD, able to recognize all AdV serotypes have to be used in this clinical setting.

\section{Acknowledgments}

We would like to thank Siemens Healthineers and Seegene for providing FTD viral GE and Allplex GI assays.

\section{Competing interest}

The authors declare no conflict of interest.

\section{References}

Afrad MH, Avzun T, Haque J, Haque W, Hossain ME, Rahman AFMR, et al. Detection of enteric-and non-enteric adenoviruses in gastroenteritis patients, Bangladesh, 20122015. J Med Virol 2018;90(4):677-84. https://doi.org/10.1002/jmv.25008.

Bányai K, Estes MK, Martella V, Parashar UD. Viral gastroenteritis. Lancet 2018;392 (10142):175-86. https://doi.org/10.1016/S0140-6736(18)31128-0.

Bennett A, Bar-Zeev N, Jere KC, Tate JE, Parashar UD, Nakagomi O, et al. Determination of a viral load threshold to distinguish symptomatic versus asymptomatic rotavirus infection in a high-disease-burden African population. J Clin Microbiol 2015;53(6): 1951-4. https://doi.org/10.1128/JCM.00875-15.

Binnicker MJ. Multiplex molecular panels for diagnosis of gastrointestinal infection: performance, result interpretation, and cost-effectiveness. J Clin Microbiol 2015;53(12): 3723-8. https://doi.org/10.1128/JCM.02103-15.
Bujang MA, Baharum N. Guidelines of the minimum sample size requirements for Cohen's kappa. Epidemiol Biostat Public Health 2017;14(2). e12267-1 https://doi.org/10. 2427/12267

Corcoran MS, Van Well GTJ, Van Loo IHM. Diagnosis of viral gastroenteritis in children interpretation of real-time PCR results and relation to clinical symptoms. Eur J Clin Microbiol Infect Dis 2014;33(10):1663-73. https://doi.org/10.1007/s10096-0142135-6.

Daniel-Wayman S, Fahle G, Palmore T, Green KY, Prevots DR. Norovirus, Astrovirus, and Sapovirus among immunocompromised patients at a tertiary care research hospital. Diagn Microbiol Infect Dis 2018;92(2):143-6. https://doi.org/10.1016/j.diagmicrobio. 2018.05.017.

Feghoul L, Chevret S, Cuinet A, Dalle JH, Ouachée M, Yacouben K, et al. Adenovirus infection and disease in paediatric haematopoietic stem cell transplant patients: clues for antiviral pre-emptive treatment. Clin Microbiol Infect 2015;21(7):701-9. https://doi org/10.1016/j.cmi.2015.03.011.

Ghosh N, Malik FA, Daver RG, Vanichanan J, Okhuysen PC. Viral associated diarrhea in immunocompromised and cancer patients at a large comprehensive cancer center: a 10-year retrospective study. Infect Dis 2017;49(2):113-9. https://doi.org/10.1080/ 23744235.2016 .1224384

Hirvonen JJ. Comparison of three multiplex real-time PCR assays for detection of enteric viruses in patients with diarrhea. Eur J Clin Microbiol Infect Dis 2019;38(2):241-4. https://doi.org/10.1007/s10096-018-3418-0.

Hum RM, Deambrosis D, Lum SH, Davies E, Bonney D, Guiver M, et al. Molecular monitoring of adenovirus reactivation in faeces after haematopoietic stem-cell transplantation to predict systemic infection: a retrospective cohort study. Lancet Haematol 2018;5(9):e422-9. https://doi.org/10.1016/S2352-3026(18)30130-3.

Hyun J, Ko DH, Lee SK, Kim HS, Kim JS, Song W, et al. Evaluation of a new multiplex realtime PCR assay for detecting gastroenteritis-causing viruses in stool samples. Ann Lab Med 2018;38(3):220-5. https://doi.org/10.3343/alm.2018.38.3.220.

Jeulin H, Salmon A, Bordigoni P, Venard V. Diagnostic value of quantitative PCR for adenovirus detection in stool samples as compared with antigen detection and cell culture in haematopoietic stem cell transplant recipients. Clin Microbiol Infect 2011;17(11): 1674-80. https://doi.org/10.1111/j.1469-0691.2011.03488.

Kapusinszky B, Minor P, Delwart E. Nearly constant shedding of diverse enteric viruses by two healthy infants. J Clin Microbiol 2012;50(11):3427-34. https://doi.org/10.1128/ JCM.01589-12.

Kosulin K, Geiger E, Vécsei A, Huber WD, Rauch M, Brenner E, et al. Persistence and reactivation of human adenoviruses in the gastrointestinal tract. Clin Microbiol Infect 2016;22(4). 381.e1-e8 https://doi.org/10.1016/j.cmi.2015.12.013.

Kosulin K, Berkowitsch B, Matthes S, Pichler H, Lawitschka A, Pötschger U, et al. Intestinal adenovirus shedding before allogeneic stem cell transplantation is a risk factor for invasive infection post-transplant. EBioMedicine 2018;28:114-9. https://doi.org/10. 1016/j.ebiom.2017.12.030.

La Rosa G, Della Libera S, Petricca S, Iaconelli M, Donia D, Saccucci P, et al. Genetic diversity of human adenovirus in children with acute gastroenteritis, Albania, 2013-2015. Biomed Res Int 2015;2015, 142912. https://doi.org/10.1155/2015/142912.

Lekana-Douki SE, Kombila-Koumavor C, Nkoghe D, Drosten C, Drexler JF, Leroy EM. Molecular epidemiology of enteric viruses and genotyping of rotavirus a, adenovirus and astrovirus among children under 5 years old in Gabon. Int J Infect Dis 2015;34: 90-5. https://doi.org/10.1016/j.ijid.2015.03.009.

Leva A, Eibach D, Krumkamp R, Käsmaier J, Rubbenstroth D, Adu-Sarkodie Y, et al. Diagnostic performance of the Luminex XTAG gastrointestinal pathogens panel to detect rotavirus in Ghanaian children with and without diarrhoea. Virol J 2016;13(1):132. https://doi.org/10.1186/s12985-016-0588-1.

Lion T. Adenovirus infections in immunocompetent and immunocompromised patients. Clin Microbiol Rev 2014;27(3):441-62. https://doi.org/10.1128/CMR.00116-13.

Lion T, Kosulin K, Landlinger C, Rauch M, Preuner S, Jugovic D, et al. Monitoring of adenovirus load in stool by real-time PCR permits early detection of impending invasive infection in patients after allogeneic stem cell transplantation. Leukemia 2010;24(4): 706. https://doi.org/10.1038/leu.2010.4.

Liu L, Qian Y, Zhang Y, Deng J, Jia L, Dong H. Adenoviruses associated with acute diarrhea in children in Beijing, China. PloS one 2014;9(2), e88791. https://doi.org/10.1371/ journal.pone.0088791.

Lu X, Erdman DD. Molecular typing of human adenoviruses by PCR and sequencing of a partial region of the hexon gene. Arch Virol 2006;151(8):1587-602. https://doi.org/ 10.1007/s00705-005-0722-7.

Lu L, Zhong H, Su L, Cao L, Xu M, Dong N, et al. Detection and molecular characterization of human adenovirus infections among hospitalized children with acute diarrhea in Shanghai, China, 2006-2011. Can J Infect Dis Med Microbiol 2017;2017(9304830). https://doi.org/10.1155/2017/9304830.

Lynch III JP, Kajon AE. Adenovirus: epidemiology, global spread of novel serotypes, and advances in treatment and prevention. Semin Respir Crit Care Med 2016;37(4): 586-602. https://doi.org/10.1055/s-0036-1584923.

Mayindou G, Ngokana B, Sidibé A, Moundélé V, Koukouikila-Koussounda F, Christevy Vouvoungui J, et al. Molecular epidemiology and surveillance of circulating rotavirus and adenovirus in Congolese children with gastroenteritis. J Med Virol 2016;88(4): 596-605. https://doi.org/10.1002/jmv.24382.

McMillen T, Lee YJ, Kamboj M, Babady NE. Limited diagnostic value of a multiplexed gastrointestinal pathogen panel for the detection of adenovirus infection in an oncology patient population. J Clin Virol 2017;94:37-41. https://doi.org/10.1016/j.jcv.2017.07.002.

Moyo SJ, Hanevik K, Blomberg B, Kommedal O, Nordbø SA, Maselle S, et al. Prevalence and molecular characterisation of human adenovirus in diarrhoeic children in Tanzania; a case control study. BMC Infect Dis 2014;14(1):666. https://doi.org/10.1186/s12879014-0666-1.

Mynarek M, Ganzenmueller T, Mueller-Heine A, Mielke C, Gonnermann A, Beier R, et al. Patient, virus, and treatment-related risk factors in pediatric adenovirus infection 
ARTICLE IN PRESS

I. Sciandra et al. / Diagnostic Microbiology and Infectious Disease $x x x(x x x x) x x x$

5

after stem cell transplantation: results of a routine monitoring program. Biol Blood Marrow Transplant 2014;20(2):250-6. https://doi.org/10.1016/j.bbmt.2013. 11.009.

Napolitano F, Ali Ado A, Vastola A, Angelillo IF. Rotavirus infection and vaccination: knowledge, beliefs, and behaviors among parents in Italy. Int J Environ Res Public Health 2019;16(10):1807. https://doi.org/10.3390/ijerph16101807.

Dude Munnink B, Van der Hoe L. Viruses causing gastroenteritis: the known, the new and those beyond. Viruses 2016;8(2):42.

Petrignani M, Verhoef L, de Graf M, Richardus JH, Koopmans M. Chronic sequelae and severa complications of norovirus infection: a systematic review of literature. J Chin Virol 2018;105:1-10. https://doi.org/10.1016/j.jcv.2018.05.004.

Phillips G, Lopman B, Tam CC, Iturriza-Gomara M, Brown D, Gray J. Diagnosing rotavirus a associated IID: using ELISA to identify a cut-off for real time RT-PCR. J Chin Virol 2009a;44(3):242-5. https://doi.org/10.1016/j.jcv.2008.12.001.

Phillips G, Lopman B, Tam CC, Iturriza-Gomara M, Brown D, Gray J. Diagnosing norovirusassociated infectious intestinal disease using viral load. BMC Infect Dis 2009b;9(1): 63. https://doi.org/10.1186/1471-2334-9-63.

Primo D, Pacheco GT, Timenetsky MDCST, Lucks A. Surveillance and molecular characterization of human adenovirus in patients with acute gastroenteritis in the era of rotavirus vaccine, Brazil, 2012-2017. J Chin Virol 2018;109:35-40. https://doi.org/10. 1016/j.jcv.2018.10.010.

Qu FZ, Shin XX, Li GX, Zhäo L, Chen C, Dunn SX, et al. Adenovirus associated with acute diarrhea: a case-control study. BMC Infect Dis 2018;18(1):450. https://doi.org/10. 1186/s12879-018-3340-1.

Ramanan P, Bryson AL, Binnicker MJ, Pritt BS, Patel R. Syndromic panel-based testing in clinical microbiology. Chin Microbiol Rev 2018;31(1). e00024-17 https://doi.org/10. 1128/CMR.00024-17.

Roos-Weil D, Ambert-Balay K, Lanternier F, Mamzer-Bruneel MF, Nochy D, Pother P, et al. Impact of norovirus/sapovirus-related diarrhea in renal transplant recipients hosptalized for diarrhea. Transplantation 2011;92(1):61-9. https://doi.org/10.1097/TP. 0b013e31821c9392.
Sadi A, Bostan N, Yinda KC, Naseem S, Sattar S. Rotavirus: genetics, pathogenesis and vaccine advances. Rev Med Virol 2018;28(6):e2003. https://doi.org/10.1002/rmv. 2003.

Trans NV, Choosy M, Nakagomi T, Chin NTM, Loan YH, Yamashiro T, et al. Determination of cutoff cycle threshold values in routine RT-PCR assays to assist differential diagnosis of norovirus in children hospitalized for acute gastroenteritis. Epidemiol Infect 2015;143(15):3292-9. https://doi.org/10.1017/ S095026881500059X.

Troeger C, Blacker BF, Khalil IA, Roo PC, Gao S, Zimsen SR, et al. Estimates of the global, regional, and national morbidity, mortality, and etiologies of diarrhoea in 195 countries: a systematic analysis for the global burden of disease study 2016. Lancet Infect Dis 2018;18(11):1211-28. https://doi.org/10.1016/S14733099(18)30362-1.

Wunderli W, Meerbach A, Guengoer T, Berger C, Greener O, Caduff R, et al. Astrovirus infiction in hospitalized infants with severe combined immunodeficiency after allongeneic hematopoietic stem cell transplantation. Plo one 2011;6(11), e27483. https:// doi.org/10.1371/journal.pone.0027483.

Yandle Z, Coughlan S, Drew RJ, Clary J, De Gascon C. Diagnosis of rotavirus infection in a vaccinated population: is a less sensitive immunochromatographic method more suitable for detecting wild-type rotavirus than real-time RT-PCR? J Chin Virol 2018; 109:19-21. https://doi.org/10.1016/j.jcv.2018.10.006.

Ye X, Van JN, Munoz FM, Kevel PA, Kozinetz CA, Trance RA, et al. Noroviruses as a cause of diarrhea in immunocompromised pediatric hematopoietic stem cell and solid organ transplant recipients. Am J Transplant 2015;15(7):1874-81. https://doi.org/10. 1111/ajt.13227.

Ye S, Whiley DM, Ware RS, Shoots TP, Kirkwood CD, Grimwood K, et al. Detection of viruses in weekly stool specimens collected during the first 2 years of life: a pilot study of five healthy Australian infants in the rotavirus vaccine era. J Med Viral 2017;89(5):917-21. https://doi.org/10.1002/jmv.24716.

Please cite this article as: I. Sciandra, L. Piccioni, L. Coltella, et al., Comparative analysis of 2 commercial molecular tests for the detection of gastroenteric viruses on stool samples, Diagnostic Microbiology and Infectious Disease, https://doi.org/10.1016/j.diagmicrobio.2019.114893 